\author{
Accelerator Department \\ BROOKHAVEN NATIONAL LABORATORY \\ Associated Universities, Inc. \\ Upton, New York 11973 \\ AGS Division Technical Note \\ No. 203 \\ FORCES AND DEFELECTIONS ON \\ NEUTRINO HORN END PLATES \\ L.E. Repeta \\ June 25,1984
}

INTRODUCTION

When neutrino horns are designed it is essential that the high energy particles (secondaries) pass through a minimum thickness of horn material to minimize their absorbtion, and yet the apparatus must maintain its structural integrity. Since the equations which describe the effects of a variable symmetrical electrical force applied to a flat circular plate are not presented in the 1iterature it was necessary to develop the required equations. The purpose of this note is to document this work. 


\begin{tabular}{|c|c|c|}
\hline $\mathrm{L}$ & self inductance & henry $=\frac{\text { volt sec }}{\text { ampere }}$ \\
\hline $\mathrm{W}$ & $\begin{array}{l}\text { energy stored in the } \\
\text { magnetic field }\end{array}$ & joules \\
\hline$\mu_{0}$ & $\begin{array}{l}\text { magnetic permeability of } \\
\text { free space }\left(4 \pi \times 10^{-7}\right)\end{array}$ & henry/meter $=\frac{\text { weber }}{\text { amp meter }}$ \\
\hline$I$ & current & amperes \\
\hline $\mathrm{k}$ & constant force & newtons; pounds \\
\hline $\mathrm{F}$ & force & newtons; pounds \\
\hline B & magnetic flux density & weber/meter ${ }^{2}$ \\
\hline $\mathrm{J}$ & current density & ampere/meter ${ }^{2}$ \\
\hline $\mathbf{r}$ & radius & inches \\
\hline a & radius of plate I.D. & meters; inches \\
\hline $\mathrm{b}$ & radius of plate $0 . D$. & meters; inches \\
\hline Q & length & meters; inches \\
\hline $\mathrm{V}$ & $\begin{array}{l}\text { shear force per unit } \\
\text { circumferential length }\end{array}$ & pounds/inch \\
\hline$\phi$ & bending ang $1 \mathrm{e}$ & radians \\
\hline$v$ & poisson's ratio & \\
\hline (1) & Deflection & inches \\
\hline D & $\begin{array}{l}\text { flexura1 rigidity of the } \\
\text { plate }\end{array}$ & pound inches \\
\hline$t$ & plate thickness & inches \\
\hline M & $\begin{array}{l}\text { bending moment per unit } \\
\text { length }\end{array}$ & pound inches/inches \\
\hline $\mathbf{E}$ & modulus of elasticity & pound / inch ${ }^{2}$ \\
\hline
\end{tabular}




\section{ELECTRICAI FORCE}

The first task is to determine the shape of the force distribution and second to evaluate its magnitude.

where,

$$
\text { force } \approx \sim \mathrm{J} \times \mathrm{B}
$$

$$
\begin{aligned}
& \text { В } \propto\left(\frac{1}{r}\right) \ldots \\
& \text { J } \propto\left(\frac{1}{r}\right) \ldots
\end{aligned}
$$

therefore,

so,

$$
\begin{gathered}
F \propto \frac{1}{r^{2}} \cdots \\
F=\frac{k}{r^{2}}
\end{gathered}
$$

The electrical force is variable and symmetrical about the cylindrical axis as shown in Figure $I$.

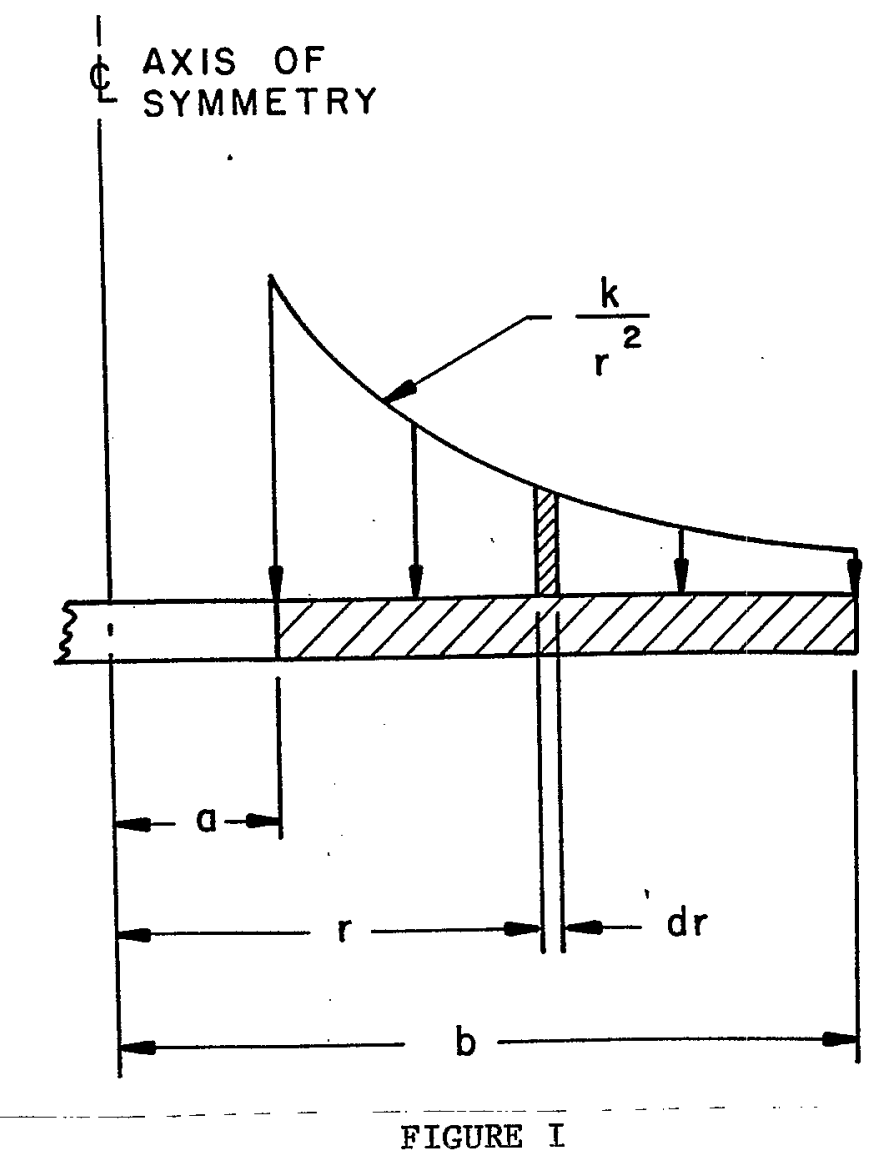




$$
\begin{gathered}
F_{\text {total }}=\int_{a}^{b} 2 \pi r d r \frac{k}{r^{2}} \\
F_{\text {tota } 1}=2 \pi k \int_{a}^{b} \frac{d r}{r}=2 \pi k \ln \frac{b}{a}
\end{gathered}
$$

The stored energy $W$ in the magnetic field of a self-inductance $L$ due to a current I flowing is

$$
W=\frac{1}{2} L I^{2}
$$

where,

$$
L=\frac{1}{2 \pi} \mu_{0} l \ln \frac{b}{a}
$$

therefore,

$$
\begin{gathered}
W / \ell=\frac{\mu_{0} I^{2}}{4 \pi} \ln \frac{b}{a} \text { (see also Appendix I) } \\
F=W / l
\end{gathered}
$$

Equate (a) and (b) and solve for $k$

$$
\begin{aligned}
& 2 \pi k \ln \frac{b}{a}=\frac{\mu_{o} I^{2}}{4 \pi} \ln \frac{b}{a} \\
& k=\frac{\mu_{o} I^{2}}{4 \pi} \ln \frac{b}{a} / 2 \pi \ln \frac{b}{a} \\
& k=\frac{\mu_{o} I^{2}}{8 \pi^{2}} \text { (newtons) }
\end{aligned}
$$

The force per unit area is

$$
F=\frac{k}{r^{2}}=\frac{\mu_{0} I^{2}}{8 \pi^{2} r^{2}}\left(\text { newtons } / \text { meter }{ }^{2}\right)
$$




\section{ASSUMPTIONS}

1. The circular plate is perfectly elastic, homogeneous and isotropic.

2. The plate is of uniform thickness.

3. The plate is initially flat.

4. The deflection of the plate is small compared to its thickness $(\omega \leq 1 / 2 t)$.

5. Deformation is symmetrical about the cylindrical axis.

6. A11 forces, loads and reactions are parallel to the cylindrical axis.

7. The shear effect on bending is negligible.

\section{MATHEMATICAL CONCEPTS}

From statics the shearing force per unit tangential length $V$ at any radius within the load distribution region, $a \leq r \leq b$ (see Figure $I$ ), is given as

$$
V=\frac{1}{2 \pi r} \int_{a}^{r} \frac{k}{r^{2}} 2 \pi r d r=\frac{k}{r} \ln \frac{r}{a}
$$

and the shear force for the unloaded region, $0 \leq \mathrm{r} \leq \mathrm{a}$, is

$$
\mathrm{V}=0
$$

The specific slope, deflection and bending moment equations obtained here are based on the derivation developed by Timoshenko in Chapter 3 of his volume Theory of Plates and She11s. ${ }^{1}$ Equation 54 from Timoshenko (rewritten below as equation 3$)^{2}$ can be used to determine the slope of the deflection surface, $\phi$, and the deflection $w$ of the plate.

$$
\frac{\mathrm{d}^{2} \phi}{\mathrm{dr}}+\frac{1}{\mathrm{r}} \frac{\mathrm{d} \phi}{\mathrm{dr}}-\frac{\phi}{\mathrm{r}^{2}}=-\frac{\mathrm{V}}{\mathrm{D}}
$$

where

$$
D=\frac{E t^{3}}{12\left(1-u^{2}\right)}
$$


The equations for the loaded region are obtained by substituting equation

(1) in (3)

$$
\begin{aligned}
& \frac{d^{2} \phi}{d r^{2}}+\frac{1}{r} \frac{d \phi}{d r}-\frac{\phi}{r^{2}}=-\frac{1}{D}\left(\frac{k}{r} \ln \frac{r}{a}\right) \\
& \frac{d}{d r}\left(\frac{1}{r} \frac{d}{d r}(r \phi)\right)=-\frac{1}{D}\left(\frac{k}{r} \ln \frac{r}{a}\right)
\end{aligned}
$$

integrate

$$
\begin{aligned}
& \frac{d}{d r}(r \phi)=-\frac{k r}{D}\left(\frac{1}{2}(\ln r)^{2}-\ln r(\ln a)\right)+c_{1}^{r} \\
& \phi=-\frac{\mathrm{d} \omega}{\mathrm{dr}}=-\frac{\mathrm{kr}}{4 \mathrm{~d}}\left(\left(\ln \frac{\mathrm{r}}{\mathrm{a}}\right)^{2}-\ln \frac{\mathrm{r}}{\mathrm{a}}-(\ln \mathrm{a})^{2}+\frac{1}{2}\right)+ \\
& \frac{C_{1} r}{2}+\frac{C_{2}}{r} \\
& \omega=\frac{k r^{2}}{8 D}\left(\left(\ln \frac{r}{a}-1\right)^{2}-(\ln a)^{2}+\frac{1}{2}\right)- \\
& \frac{c_{1} r^{2}}{4}-c_{2} \ln r+c_{3}
\end{aligned}
$$

The equations for the unloaded region are obtained by substituting equation (2) in (3)

$$
\frac{d}{d r}\left(\frac{1}{r} \frac{d}{d r}(\phi r)\right)=-\frac{1}{D}(0)
$$

integrate

$$
\frac{d}{d r}(r \phi)=c_{4} r
$$




$$
\begin{aligned}
& \phi=-\frac{d w}{d r}=-\frac{C_{4} r}{2}+\frac{C_{5}}{r} \\
& \omega=-\frac{C_{4} r^{2}}{4}-C_{5} \ln r+C_{6} .
\end{aligned}
$$

The bending moments for the loaded region of the plate are obtained by substituting the expressions for $\phi$ (equation 4) and $\mathrm{d} \phi / \mathrm{dr}$ (equation 8) in Timoshenko's equations (52) and (53) rewritten below as equations (9) and (10). 3

$$
\begin{aligned}
& \frac{d \phi}{d r}=-\frac{k r}{4 D}\left(2\left(\ln \frac{r}{a}\right) \frac{1}{\frac{r}{a}}\left(\frac{1}{a}\right)-\frac{1}{r}\right)- \\
& \frac{k}{4 D}\left(\left(\ln \frac{r}{a}\right)^{2}-\ln \frac{r}{a}-(\ln a)^{2}+\frac{1}{2}\right)+ \\
& \frac{C_{1}}{2}-\frac{C_{2}}{r^{2}} \\
& \frac{d \phi}{d r}=-\frac{k r}{4 D}\left(2\left(\ln \frac{r}{a}\right)\left(\frac{1}{r}\right)-\frac{1}{r}\right)- \\
& \frac{k}{4 D}\left(\left(\ln \frac{r}{a}\right)^{2}-\ln \frac{r}{a}-(\ln a)^{2}+\frac{1}{2}\right)+ \\
& \frac{C_{1}}{2}-\frac{C_{2}}{r^{2}} \\
& M_{r}=D\left(\frac{d \phi}{d r}+\frac{U}{r} \phi\right) \\
& M_{t}=D\left(\frac{\phi}{r}+v \frac{d \phi}{d r}\right)
\end{aligned}
$$

The constants of integration $C_{1}, C_{2}$ and $C_{3}$ are determined from the boundary conditions at the edge and center of the circular plate. The neutrino horn end plates have their outer edge fixed and supported, and the inner edge fixed as depicted in Figure II. 


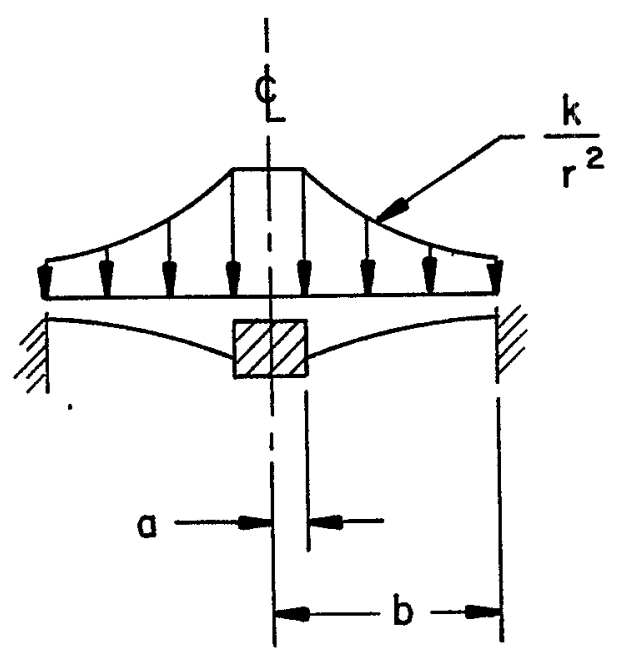

FIGURE II

The boundary conditions for this case are

$$
\begin{aligned}
& \frac{d \omega}{d r}=0 \text { when } r=a \\
& \frac{d \omega}{d r}=0 \text { when } r=b \\
& \omega=0 \text { when } r=b
\end{aligned}
$$

The three equations to be solved to obtain the constants of integration for this case are

$$
\begin{gathered}
0=-\frac{k a}{4 d}\left(\frac{1}{2}-(\ln a)^{2}\right)+\frac{C_{1} a}{2}+\frac{C_{2}}{a} \\
0=-\frac{k b}{4 D}\left(\left(\ln \frac{b}{a}\right)^{2}-\ln \frac{b}{a}-(\ln a)^{2}+\frac{1}{2}\right)+\frac{C_{1} b}{2}+\frac{C_{2}}{b} \\
0=\frac{k b}{8 D}\left[\left(\ln \frac{b}{a}-1\right)^{2}-(\ln a)^{2}+\frac{1}{2}\right)-\frac{C_{1} b}{4}-C_{2} \ln b+c_{3}
\end{gathered}
$$


Since the equations for the slope, deflection and bending moments are best solved by computer no attempt has been made to substitute equations (4) and (8) in (9) and (10), or substitute the constants of integration in equations (4) and (5) and simplify the results. A large amount of time would be required to do these manipulations; the chances for error in this process are large, and the time saved doing the calculation by computer is negligable.

After the maximum bending moment has been determined the maximum stress is evaluated using 4

$$
\mathrm{S}_{\max }=\frac{6 \mathrm{M}_{\max }}{t^{2}}
$$

The boundary conditions for three other edge support conditions are listed below.

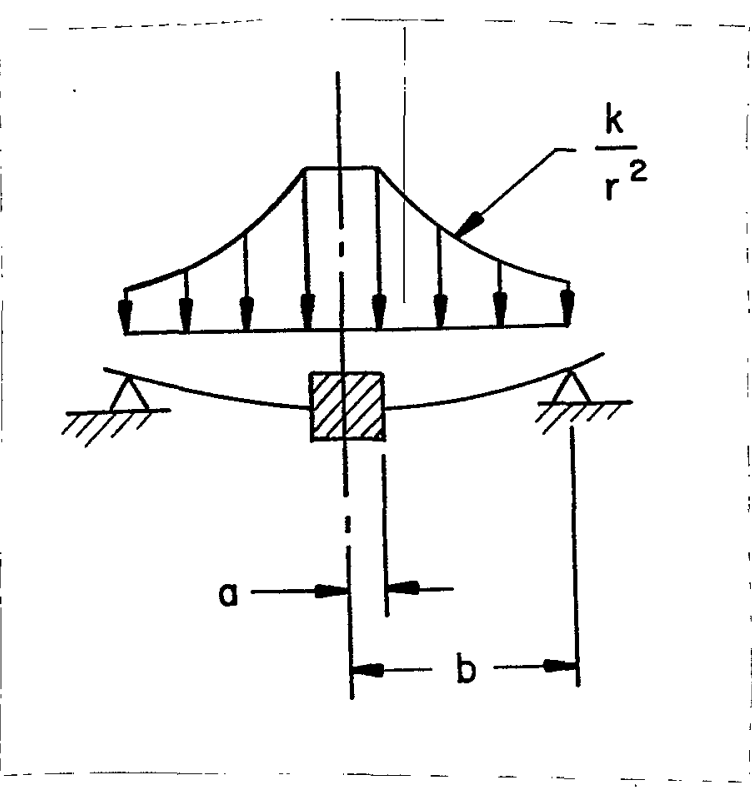

EDGE CONDITIONS

Outer edge simply supported.

Inner edge fixed.

BOUNDARY CONDITIONS

$$
\begin{aligned}
\omega & =0 \text { when } r=b \\
M_{r} & =0 \text { when } r=b \\
\frac{d}{d r} & =0 \text { when } r=a
\end{aligned}
$$




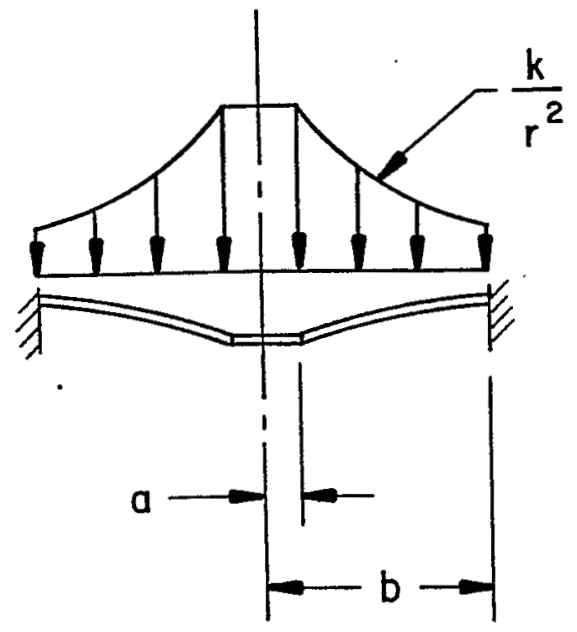

BOUNDARY CONDITIONS

$\omega=0$ when $\mathrm{r}=\mathrm{b}$

$\frac{d \omega}{d r}=0$ when $r=b$

$M_{r}=0$ when $r=a$

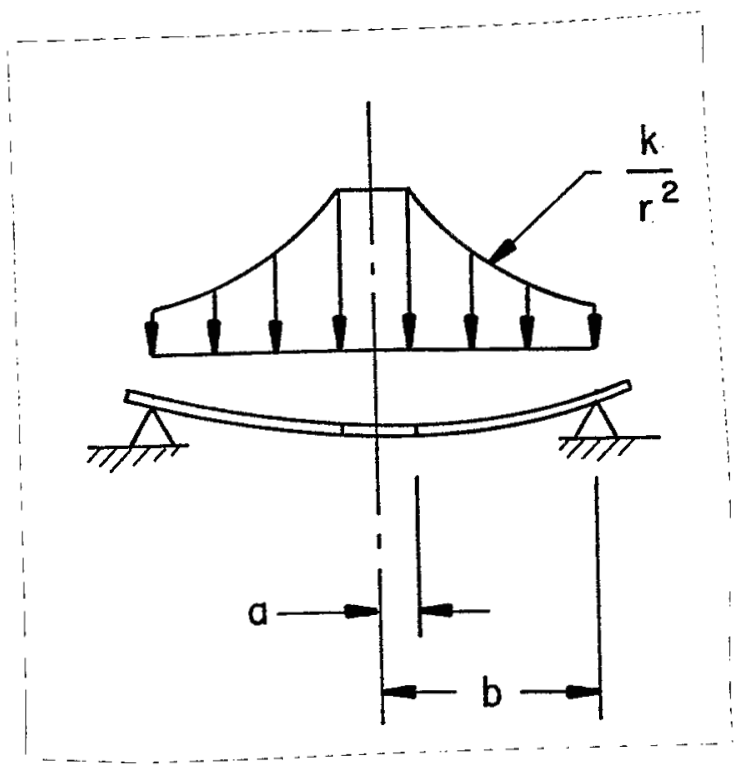

BOUNDARY CONDITIONS

$\omega=0$ when $r=b$

$M_{r}=0$ when $r=b$

$M_{r}=0$ when $r=a$
EDGE CONDITIONS

Outer edge supported and fixed.

Inner edge free.

\section{EDGE CONDITIONS}

Outer edge simply supported.

Inner edge free. 


\section{APPENDIX I}

FORCE ON END PLATE ${ }^{5}$

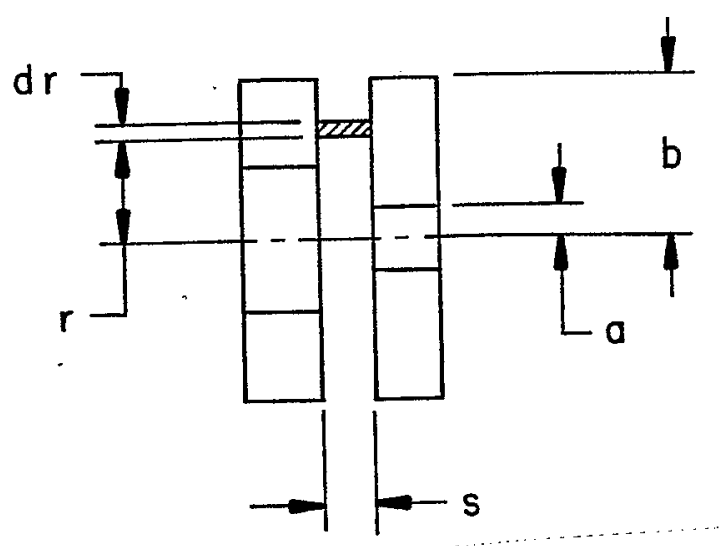

$$
\begin{aligned}
w_{m}= & \text { Energy density of } \\
& \text { magnet field } \\
& \left(\text { joules } / \mathrm{m}^{3}\right)
\end{aligned}
$$

$\mathrm{H}$ = Magnetic field intensity (amp/m)

$v=$ volume $\left(\mathrm{m}^{3}\right)$

$$
\begin{aligned}
& W=\int_{v} w_{m} d v=\frac{1}{2} \int_{v} \mu_{o} H^{2} d v \\
& W=\frac{1}{2} \int_{a}^{b} \int_{0}^{2 \pi} \mu_{o} H^{2} s r d r d \theta \\
& W=\left.\frac{1}{2} S \int_{a}^{b} \mu_{o} H^{2} r d r\right|_{o} ^{2 \pi} \\
& W=\frac{1}{2}(2) \pi S \mu_{o_{a}} \int^{b} H^{2} r d r=\pi S \mu_{o} \int_{a}^{b} H^{2} r d r \\
& B(\text { at } r)=\frac{\mu_{0} I}{2 \pi r} \\
& \mathrm{H}=\frac{\mathrm{B}}{\mu_{\mathrm{o}}}=\frac{\mathrm{I}}{2 \pi r} ; \mathrm{H}^{2}=\frac{\mathrm{I}^{2}}{4 \pi^{2} \mathrm{r}^{2}} \\
& W=\pi S \mu_{0} \frac{I^{2}}{4 \pi^{2}} \int_{a}^{b} \frac{r}{r^{2}} d r=\frac{\mu_{o} S I^{2}}{r \pi} \int_{a}^{b} \frac{d r}{r} \\
& W=\frac{\mu_{0} S I^{2}}{4 \pi} \ln \frac{b}{a}
\end{aligned}
$$

then,

$$
F=-\frac{d W}{d S}=-\frac{\mu_{o} I^{2}}{4 \pi} \ln \frac{b}{a} \text { (newtons) }
$$


FOOTNOTES

1. Timoshenko, S. and Woinowsky-Krieger, S., The Theory of Plates and She11s, McGraw-Hi11 Book Co., Inc., 1959, pp. 51-78.

2. IBID., P. 53 .

3. IBID., P. 52 .

4. IBID., p. 42

5. Kraus, John D., Electromagnetics, McGraw Hil1 Book Co., Inc. 1953, Pp. $264-265$

WPC

Distribution: Dept. S\&P 